\title{
Pengaruh Penambahan Konsentrasi Pasir Besi dalam Resin Epoksi pada Sifat Korosi Besi Karbon
}

\author{
Linda Silvia* dan Mochamad Zainuri \\ Jurusan Fisika, Fakultas Matematika dan Ilmu Pengetahuan Alam, \\ Institut Teknologi Sepuluh Nopember (ITS), Kampus ITS Sukolilo, Surabaya 60111
}

Intisari

\begin{abstract}
Telah dilakukan penelitian mengenai pengaruh penambahan konsentrasi pasir besi dalam resin epoksi terhadap sifat korosi besi karbon. Metode separasi sederhana pasir besi dilakukan dengan menggunakan magnet. Eksperimen dilakukan dengan mengontrol konsentrasi pasir besi dengan variasi komposisi 0\%wt, 10\%wt, $30 \%$ wt, dan $50 \%$ wt dari total berat komposit, kemudian dilapiskan pada baja karbon dan dikeringkan pada temperatur ruang. Komposit yang telah terbentuk direndam ke dalam larutan $\mathrm{NaCl} 10 \mathrm{M}$ selama 21 hari dan selanjutnya diuji laju korosi. Karakteristik pasir besi diamati dengan $X$-Ray Diffractometer (XRD) yang digunakan untuk mengidentifikasi fasa pasir besi dan X-Ray Flourescence (XRF) untuk mengukur komposisi elemen dan oksida dari pasir besi. Laju korosi material komposit yang dihasilkan diuji dengan menggunakan metode kehilangan massa. Berdasarkan hasil analisa pengukuran laju korosi menggunakan metode kehilangan massa diperoleh laju korosi terbesar terjadi pada penambahan konsentrasi pasir besi 30\%wt yaitu 71,9246 mpy dan laju korosi mengalami penurunan terjadi pada 50\%wt dari total berat komposit adalah 12,5379 mpy, dimana memiliki ketahanan korosi yang lebih baik sehingga dapat digunakan sebagai pelapis cat kapal laut.
\end{abstract}

\begin{abstract}
The effect of adding iron sand concentration in epoxy resin on the corrosion rate of carbon steel had been studied with mass loss method measurement. In this research work, iron sand was separated by magnet and iron sand/epoxy composites coating applied to carbon steel. Experiments was carried out by controlling concentration of iron sand with variation in composition $0 \% \mathrm{wt}, 10 \% \mathrm{wt}, 30 \% \mathrm{wt}$, and $50 \% \mathrm{wt}$ of the weight composites total, and then carbon steel was immersion at $\mathrm{NaCl} 10 \mathrm{M}$ and drying at room temperature. The composite has been formed is immersed into a solution of $10 \mathrm{M} \mathrm{NaCl}$ for 21 days and then tested the corrosion rate. The composites were characterized using X-Ray Diffractometer (XRD) for phase identification of iron sand and $\mathrm{X}$-ray fluorescence (XRF) for measure composition of elements and oxides of iron sand. Corrosion rate of composite materials was indentified with mass loss method. The results showed that analysis of the corrosion rate measurements obtained the largest mass loss of corrosion rate occur in concentrations addition of $30 \%$ wt of the weight composites total was $71.9246 \mathrm{mpy}$ and the corrosion rate of decline occurred in $50 \% \mathrm{wt}$ of the weight composites total was 12.5379 mpy, which has good corrosion resistance that can be used as a coating of ships paint.
\end{abstract}

KATA KUNCI: corrosion, composites, corrosion rate, XRD, XRF

\section{PENDAHULUAN}

Korosi merupakan salah satu permasalahan penting yang harus dihadapi oleh berbagai macam sektor industri di Indonesia, terutama industri perkapalan. Tidak sedikit biaya yang harus dikeluarkan sebagai akibat langsung dari masalah tersebut. Menyadari keadaan ini, pengendalian masalah korosi dan penanggulangannya perlu dilakukan dengan lebih efektif terutama pada aplikasi alat-alat penunjang produksi pada kondisi-kondisi ekstrem seperti pada lingkungan dengan kadar $\mathrm{Cl}, \mathrm{H}_{2} \mathrm{~S}, \mathrm{O}_{2}, \mathrm{H}_{2}$ yang tinggi dan kondisi lainnya, agar dapat berjalan lebih efektif, efisien, dan optimal. Salah satu jenis antikorosi saat ini yang digunakan sebagai penunjang

\footnotetext{
${ }^{*}$ E-MAIL: linda@physics.its.ac.id
}

sektor industri terdapat dalam bentuk bahan pelapis (cat) yang efisien sebagai material pelapis anti korosi. Kemampuan cat memberikan perlindungan antikorosi ke substrat logam diatur oleh komposisi kimia dan konsentrasi dalam pengikat bahan pelapis [1].

Interaksi dengan lingkungan merupakan salah satu penyebab terjadinya penurunan mutu material [2]. Di dalam proses korosi ada dua unsur pokok yang terlibat langsung yaitu material dan lingkungan. Material terutama logam dan paduannya bertindak sebagai objek korosi sedangkan lingkungan seperti udara, air, permukaan lembab, dan bahan kimia bertindak sebagai media korosif. Dalam banyak hal korosi tidak dapat dicegah tetapi hanya dapat dikendalikan, Langkah awal yang tepat dilakukan yaitu dengan memberi proteksi terhadap suatu bahan sehingga bahan tersebut bersifat katodik. Salah satu cara yang digunakan adalah dengan memasang anoda-anoda tumbal pada struktur yang sering terserang korosi. Pada tahun 
1824, Sir Humphrey Davy melaporkan keberhasilan penggunaan anoda seng untuk melindungi pelapis tembaga pada kapal perang [3].

Perkembangan saat ini resin epoksi telah berkembang pesat sejak ditemukan dan banyak digunakan dalam kehidupan modern [4-6]. Dalam hal ini, matrik yang digunakan adalah resin epoksi karena secara luas sering digunakan sebagai material pelapis baja, mudah diproses, ketahanan kimia yang baik, isolator listrik yang baik, dan mempunyai gaya tarik menarik yang kuat antara berbagai macam material [7]. Namun resin epoksi mempunyai ketahanan terhadap ultraviolet yang lemah, sehingga dalam hal ini akan ditambahkan pasir besi sebagai filler sehingga dapat dimanfaatkan sebagai pelapis antikorosi serta dapat mengurangi pengaruh ultraviolet terhadap pelapisan komposit tersebut.

Suatu bahan dapat dikatakan tahan terhadap korosi bila laju korosinya lebih kecil dari 50 mpy. Laju korosi merupakan besaran yang menyatakan mudah/tidaknya suatu material berinteraksi dengan lingkungannya. Metode yang sering digunakan untuk menentukan laju korosi adalah metode kehilangan massa, dengan mengukur perbedaan massa awal sebelum pengujian dengan massa akhir setelah pengujian korosi. Laju korosi biasanya dinyatakan dalam mil per tahun (mpy), dapat dirumuskan sebagai berikut [3]:

$$
\text { Laju korosi }=\frac{534 \times W_{\ell}}{\rho \times A \times t}
$$

$\mathrm{W}_{\ell}$ merupakan massa yang hilang $(\mathrm{mg}), \rho$ adalah massa jenis $\operatorname{logan}\left(\mathrm{gr} / \mathrm{cm}^{3}\right)$, A adalah luas permukaan specimen (inchi $\left.{ }^{2}\right)$, dan $t$ adalah waktu pencelupan (jam). Pers.(1) tersebut dapat diperoleh besarnya laju korosi benda uji.

Pada penelitian ini pasir besi sebagai filler dengan matrik berupa resin epoksi sehingga didapatkan komposit epoksipasir besi yang kemudian dilapiskan pada permukaan besi karbon sehingga dapat digunakan sebagai material antikorosi pada pelapis cat kapal laut. Komposit epoksi-pasir besi tersebut berfungsi sebagai anoda-anoda tumbal pada struktur yang sering terserang korosi, dalam hal ini besi karbon. Material dasar pembentuk komposit pada penelitian ini akan diuji dengan XRD yang digunakan untuk mengidentifikasi fasa-fasa yang ada pada suatu material. Identifikasi fasa merupakan pencocokan data posisi-posisi puncak difraksi terukur dengan database fasa-fasa dalam bentuk kartu PDF (Powder Diffraction File) [8] dan XRF yang digunakan untuk mengetahui komposisi elemen dan oksida dari suatu material. Kemudian komposit yang diperoleh dapat diketahui laju korosinya dengan metode kehilangan massa, yang divariasikan dengan penambahan konsentrasi pasir besi yang berfungsi sebagai filler.

\section{METODOLOGI PENELITIAN}

\section{Preparasi sampel}

Dalam penelitian ini digunakan benda uji berupa besi karbon yang berbentuk silinder dengan tinggi $1 \mathrm{~cm}$ dan diameter
0,5 cm kemudian benda uji dipolish agar bekas pemotongan lebih halus dan rata. Proses polishing dilakukan dengan menggunakan kertas amplas dengan grade 400, 600, 800, dan 1000. Specimen uji dicuci dengan ultrasonic cleaner dalam ethanol selama 15 menit dan dikeringkan di udara. Pembuatan komposit dilakukan dengan mencampurkan resin epoksi sebagai matrik dengan pasir besi sebagai filler pada temperatur ruang. Separasi pasir besi dilakukan dengan menggunakan magnet untuk memisahkan dari pengotor. Pasir besi yang telah diperoleh dibersihkan menggunakan ultrasonic cleaner dengan media aquades kemudian didrying $100^{\circ} \mathrm{C}$ menggunakan oven selama 2 jam. Pasir besi yang diperoleh diseparasi untuk kedua kalinya menggunakan magnet dan dicampurkan ke dalam resin epoksi menggunakan magnetic strirrer selama 15 menit dengan perbandingan variasi konsentrasi 0\%wt, $10 \%$ wt, $30 \%$ wt, dan $50 \%$ wt dari total berat komposit dan dilapiskan pada permukaan besi karbon. Pelapisan dilakukan dengan cara memasukkan specimen uji ke dalam larutan komposit tersebut, kemudian diangkat dan dikeringkan pada temperatur ruang.

\section{Karakterisasi sampel}

Pasir besi yang telah diseparasi dengan menggunakan magnet dan diberi perlakuan panas $100^{\circ} \mathrm{C}$ selama 2 jam dikarakterisasi dengan XRD dan XRF. Komposit yang telah terbentuk direndam ke dalam larutan $\mathrm{NaCl} 10 \mathrm{M}$ selama 21 hari dan dilakukan pengujian dengan menggunakan metode kehilangan massa untuk mengetahui laju korosi material komposit tersebut. Proses korosi pertama yang dilakukan dengan menggunakan pelapis epoksi tanpa adanya kandungan pasir besi pada komposit tersebut, kemudian uji korosi yang kedua dilakukan dengan adanya kandungan pasir besi dengan variasi konsentrasi yang berbeda-beda. Pengujian korosi dilakukan pada temperatur ruang. Setelah benda uji kering, ditimbang untuk mengetahui berat akhirnya.

\section{HASIL DAN PEMBAHASAN}

\section{Analisis menggunakan metode Search Match}

Bahan pelapis yang akan dibuat berupa resin epoksi sebagai matrik dan pasir besi sebagai filler dengan variasi konsentrasi filler sebesar 0\%wt, 10\%wt, 30\%wt, dan 50\%wt dari total berat komposit. Pasir besi yang telah diseparasi dengan menggunakan magnet kemudian dibersihkan menggunakan ultrasonic cleaner dengan media aquades dan diberi perlakuan panas $100^{\circ} \mathrm{C}$ menggunakan oven selama 2 jam di uji dengan menggunakan XRD. Hasilnya akan dianalisis dengan menggunakan metode search match seperti ditunjukkan pada Gambar 1.

Metode search match digunakan untuk mengetahui hasil XRD dengan data yang telah dimiliki oleh software, dimana dapat diketahui fasa-fasa yang terdapat dalam material. Berdasarkan Gambar 1 pola XRD pasir besi dan hasil search match dapat diketahui bahwa puncak-puncak yang teridentifikasi kebanyakan adalah magnetite $\left(\mathrm{FeO} \mathrm{Fe}_{2} \mathrm{O}_{3}\right)$ dimana 


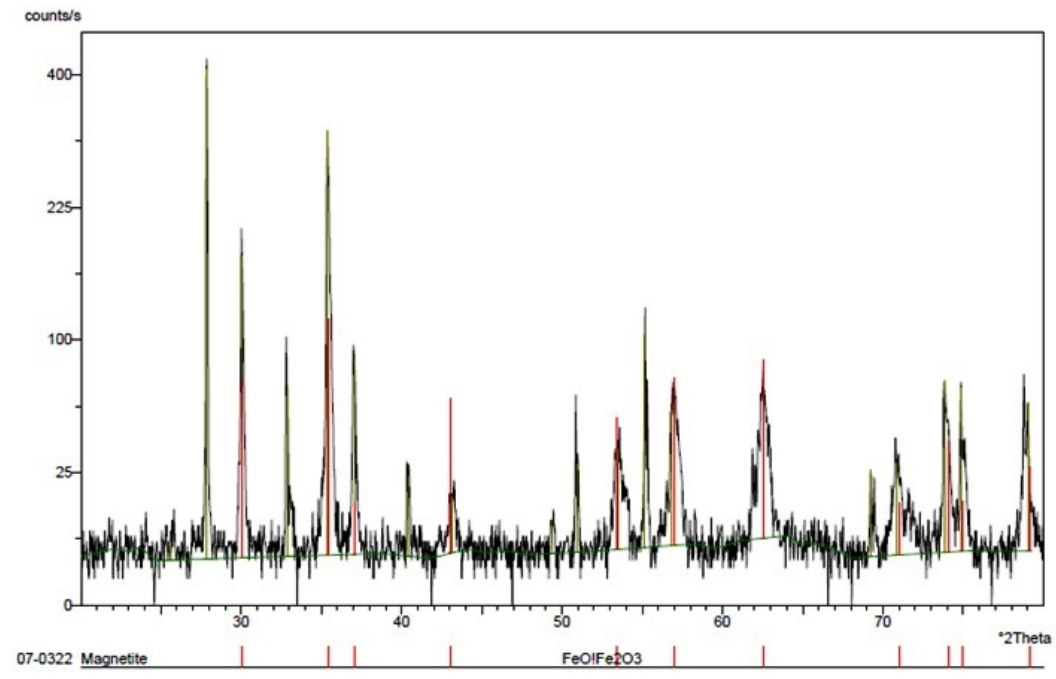

Gambar 1: Pola X-Ray Diffractometer (XRD) pasir besi.

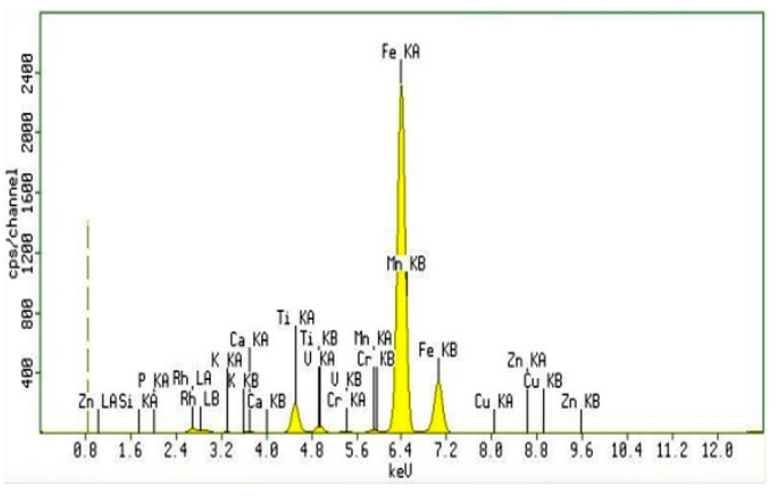

Gambar 2: Hasil uji X-Ray Flourescence (XRF) pasir besi.

satu bagian adalah wustite $(\mathrm{FeO})$ dan bagian lainnya adalah hematit $\left(\mathrm{Fe}_{2} \mathrm{O}_{3}\right)$, namun ada beberapa fasa lain, dimana ditunjukkan adanya puncak yang belum teridentifikasi oleh metode search match. Oleh karena itu selanjutnya dilakukan pengujian XRF yang dapat mengetahui komposisi elemen dan oksida dari suatu material. Hasil uji XRF ditunjukkan pada Gambar 2.

Pengujian XRF pada pasir besi berfungsi sebagai validasi dari presentasi unsur-unsur yang membentuk pasir besi tersebut. Berdasarkan hasil uji XRF ditunjukkan bahwa kandungan terbanyak unsur pembentuk pasir besi adalah besi $(\mathrm{Fe})$ sebesar 89,93\% dan Titanium (Ti) sebesar 6,87\%, sedangkan prosentase lainnya berupa Silikon (Si), Pospor (p), Potasium (K), Kalsium (Ca), Vanadium (V), Kromium (Cr), Manganese $(\mathrm{Mn})$, Copper $(\mathrm{Cu})$, dan Zinc $(\mathrm{Zn})$ yang ditunjukkan seperti pada Gambar 2. Oksida yang banyak terbentuk pada pasir besi berupa Iron Oxide $\left(\mathrm{Fe}_{2} \mathrm{O}_{3}\right)$ dan Titanium Oxide $\left(\mathrm{TiO}_{2}\right)$.

\section{Pengujian laju korosi}

Pada penelitian ini, matrik yang digunakan adalah resin epoksi karena secara luas sering digunakan sebagai material pelapis baja, mudah diproses, ketahanan kimia yang baik, isolator listrik yang baik, dan mempunyai gaya tarik menarik yang kuat antara berbagai macam material [7]. Resin epoksi berfungsi sebagai perekat/binder pada komposit. Pencampuran resin epoksi dengan pasir besi menggunakan magnetic strirrer selama 15 menit dengan perbandingan variasi konsentrasi $0 \%$ wt, $10 \%$ wt, $30 \%$ wt, dan $50 \%$ wt dari total berat komposit. Kemudian besi karbon yang telah dipoles, dimasukkan ke dalam campuran tersebut, diangkat dan disimpan ditempat yang kering pada temperatur ruang, kemudian diuji korosi dengan menggunakan metode kehilangan massa dengan menggunakan media korosi berupa $\mathrm{NaCl} 10 \mathrm{M}$ dan direndam selama 21 hari. Laju korosi yang terjadi dihitung menggunakan metode kehilangan massa yaitu benda uji yang telah dipersiapkan ditimbang terlebih dahulu dengan digital balance sebelum dan sesudah pengujian korosi, ditunjukkan pada Tabel I.

Benda uji yang telah diuji korosi tersebut akan diketahui laju korosinya dengan menggunakan metode kehilangan massa (mass loss) menggunakan Pers.(1). Selisih massa awal dan massa akhir akan menentukan laju korosi dari sampel. Berdasarkan data hasil perhitungan laju korosi, maka dapat diperoleh grafik hubungan antara konsentrasi filler dan laju korosi sebagai berikut ditunjukkan pada Gambar 3.

Berdasarkan hasil analisis pengukuran laju korosi menggunakan metode kehilangan massa diperoleh laju korosi terbesar terjadi pada penambahan konsentrasi pasir besi $30 \% \mathrm{wt}$ yaitu 71,9246 mpy dan laju korosi mengalami penurunan terjadi pada 50\%wt dari total berat komposit adalah 12,5379 mpy, dimana memiliki ketahanan korosi yang lebih baik sehingga dapat digunakan sebagai pelapis cat kapal laut. Hal ini terjadi karena lapisan yang digunakan berfungsi sebagai anoda-anoda tumbal pada struktur yang sering terserang korosi karena banyak mengandung $\mathrm{Fe}_{2} \mathrm{O}_{3}$. Pada saat penambahan konsentrasi pasir besi $30 \%$ wt terjadi peningkatan laju 
TABEL I: Data massa sampel dengan variasi konsentrasi pasir besi $0 \% \mathrm{wt}, 10 \% \mathrm{wt}, 30 \% \mathrm{wt}$, dan $50 \% \mathrm{wt}$ dari total berat komposit.

\begin{tabular}{cccccc}
\hline \hline \multicolumn{2}{c}{ Pasir } & Resin & \multicolumn{4}{c}{ M a s s a } & \multicolumn{3}{c}{ k o m p o s i t (gr) } \\
Besi & $\begin{array}{c}\text { Epoksi } \\
\text { (gr) }\end{array}$ & (gr) & sebelum direndam & \multicolumn{3}{c}{ setelah direndam NaCl 10 M } \\
& $\mathrm{NaCl} 10 \mathrm{M}$ & 7 hari & 14 hari & 21 hari \\
\hline 0 & 5 & 3,6972 & 3,7130 & 3,7134 & 3,7132 \\
0,5 & 4,5 & 3,5891 & 3,6393 & 3,6399 & 3,6418 \\
1,5 & 3,5 & 3,5570 & 3,7813 & 3,7834 & 3,7858 \\
2,5 & 2,5 & 3,5697 & 3,6847 & 3,6853 & 3,6870 \\
\hline \hline
\end{tabular}

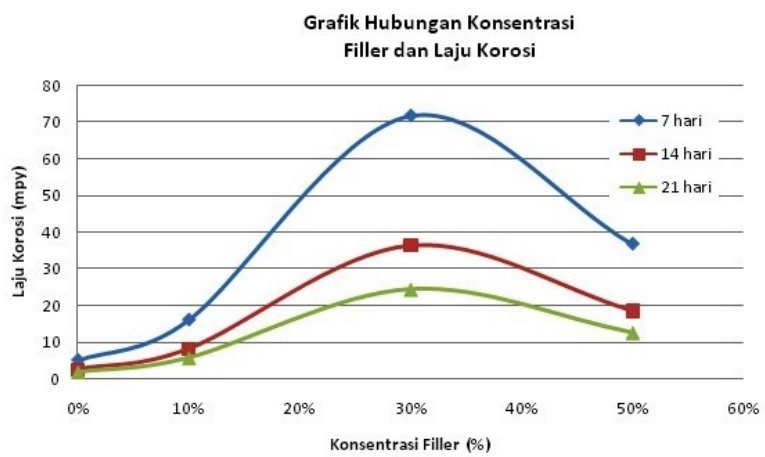

Gambar 3: Grafik hubungan konsentrasi filler dan laju korosi.

korosi yang sangat drastis karena adanya partikel yang bergerombol sehingga menyebabkan adanya perbedaan potensial kimia dan tercipta anoda katoda baru yang dapat menyebabkan korosi. Ketika sampel direndam ke dalam larutan $\mathrm{NaCl}$, ion-ion pengkorosif memiliki muatan negatif yang akan tarik menarik dengan mutan positif, sehingga ion-ion pengkorosif akan terlebih dahulu mengkorosi bagian luar lapisan komposit tersebut, seperti $\mathrm{Fe}_{2} \mathrm{O}_{3}$ yang terkandung dalam pasir besi. Sedangkan ketika penambahan konsentrasi $50 \%$ wt dari total berat komposit terjadi penurunan laju korosi karena pasir besi dapat tersebar merata ke seluruh bagian sehingga terjadinya penetrasi ke lubang kecil, lekukan, dan kapiler pada daerah pelapisan yang dapat mengurangi korosi pada pelapisan logam tersebut seperti yang telah dilakukan Xianming Shi, et al. [6] mengenai penelitian $\mathrm{Fe}_{2} \mathrm{O}_{3}$ yang dapat mengurangi laju korosi. Selain $\mathrm{Fe}_{2} \mathrm{O}_{3}$, faktor pengisi juga mengandung sedikit $\mathrm{TiO}_{2}$, dimana konsentrasi $\mathrm{TiO}_{2}$ juga memberikan pengaruh terhadap ketahanan korosi dari komposit tersebut. Penambahan konsentrasi pengisi $\mathrm{TiO}_{2}$ dapat berdampak meningkatkan ketahanan korosi dan juga da- pat menurunkan ketahanan korosi. Penambahan $\mathrm{TiO}_{2}$ yang berlebihan akan memberikan dampak negatif yaitu penurunan ketahanan korosi.

Dalam hal ini, secara sederhana korosi dari suatu material dapat diartikan sebagai perubahan logam menjadi ion logam yang diakibatkan terlepasnya elektron dari atom logam pada struktur padatnya. Besi karbon yang berada dalam lingkungan asam dapat mengalami penurunan kualitas karena adanya reaksi antara besi karbon dengan lingkungan yang korosif, dimana reaksi korosi dapat menyebabkan penurunan kualitas besi karbon karena serangan ion-ion $\mathrm{Cl}$ pada bagian permukaan. Besi karbon akan mengalami peningkatan serangan korosi oleh ion-ion $\mathrm{Cl}$ seiring dengan berjalannya waktu. Ketika semakin tebal lapisan pelindung, maka semakin sulit komponen-komponen tersebut masuk, tetapi meskipun banyak lapisan yang tidak dapat ditembus ion-ion seperti klorida, namun belum ada lapisan yang sepenuhnya mampu menghalangi oksigen atau air. Bila tiba saatnya, oksigen atau air akan berhasil mencapai permukaan logam dan dengan demikian lapisan tidak mampu menghalangi reaksi katoda, sehingga terjadilah korosi. Oleh karena itu efek perlindungan terhadap korosi juga tergantung pada metode perlakuan permukaan logam dan sejumlah faktor lainnya [9].

\section{SIMPULAN}

Berdasarkan hasil analisis pengukuran laju korosi menggunakan metode kehilangan massa diperoleh laju korosi terbesar terjadi pada penambahan konsentrasi pasir besi $30 \%$ wt yaitu 71,9246 mpy dan laju korosi mengalami penurunan terjadi pada 50\%wt dari total berat komposit adalah 12,5379 mpy, dimana memiliki ketahanan korosi yang lebih baik sehingga dapat digunakan sebagai pelapis cat kapal laut
[1] H. Kukackova, A. Vrastilova, A. Kalendova, Phys. Proc., 44, 238-246 (2013).

[2] K.R. Trethewey, and John Chamberlain, Korosi Untuk Mahasiswa Sains dan Rekayasa (PT. Gramedia Pustaka Utama, Jakarta, 1991).

[3] M. Fontana, Corrosion Engineering (Mc.Graw Hill Book Company, America, 1986).

[4] I. Hamerton, B.J. Howlin, P. Jepson, Coord. Chem. Rev., 224, 67-85 (2002).
[5] M. Blanco, et al., Polymer, 46, 7989-8000 (2005).

[6] F. Delor-Jestin, et al., Polym. Degrad. Stabil., 91, 1247-1255 (2006).

[7] X. Shi, et al., Surface and Coatings Technology, 204, 237-245 (2009).

[8] S. Pratapa, Analisis Data Difraksi Menggunakan Rietveld (ITS Surabaya, 2009).

[9] E.W. Brooman, Metal Finishing (Ohio, 2002). 